\title{
Studies on the Chemical Composition of Lipopolysaccharide from Neisseria meningitidis Group B
}

\author{
By GUADALUPE A. LIMJUCO, Y. D. KARKHANIS, \\ JOHANNA Y. ZELTNER, R. Z. MAIGETTER, \\ J. J. KING AND D. J. CARLO \\ The Merck Institute for Therapeutic Research, Rahway, New Jersey 07065, U.S.A.
}

(Received 9 August 1977; revised 17 October 1977)

\begin{abstract}
A lipopolysaccharide was isolated from Neisseria meningitidis group B by phenol/water extraction and purified by differential ultracentrifugation. This preparation exhibited endotoxic properties as shown by the limulus-lysate assay. Mild acid hydrolysis of the lipopolysaccharide yielded a lipid A fraction and a polysaccharide fraction. The lipid A fraction contained fatty acids, phosphorus and glucosamine. Analysis of the polysaccharide fraction revealed the presence of glucose, galactose, glucosamine, 2-keto-3-deoxyoctonic acid and phosphorus. There was no heptose.
\end{abstract}

\section{INTRODUCTION}

The pathological and physiological effects of meningococcal infections have been associated with the endotoxic properties of the bacteria (Scherp, 1955; Thomas, 1954; Burrows, 1951). Although metabolic effects of meningococcal endotoxin have been reported (Kun, 1947; Kun \& Abood, 1949), there are relatively few studies on the composition and structure of the lipopolysaccharide (LPS) of Neisseriaceae, whereas the LPS of the Enterobacteriaceae has been extensively studied. Boivin \& Mesrobeanu (1933) first isolated a carbohydratelipid complex from meningococcus by trichloroacetic acid extraction. This substance was toxic for animals, and although protein-free it was antigenic and immunogenic. These investigators regarded the preparation as a somatic antigen and designated it antigen 'complet'. Boor \& Miller (1944) isolated glycolipids which were both toxic and antigenic from various strains of Neisseria. They used three different extraction procedures: (i) trichloroacetic acid, (ii) $0.5 \mathrm{M}$-hydrochloric acid and (iii) diethylene glycol, all of which gave similar products. These were polysaccharides containing phosphorus and nitrogen bound to a phospholipid. Mergenhagen, Martin \& Schiffmann (1963) isolated the LPS from Neisseria meningitidis group C, and found that it was $20 \%$ lipid and contained glucose, galactose, glucosamine and sialic acid. Yamakawa \& Ueta (1964) studied the carbohydrate and fatty acid composition of whole organisms of $N$. meningitidis (groups $\mathrm{A}, \mathrm{B}, \mathrm{C}$ and $\mathrm{D}$ ), $N$. flavescens, $N$. perflava, $N$. haemolysans and $N$. gonorrhoeae. Neisseria haemolysans differed from the other Neisseria species in the composition of both fatty acids and sugars. An extensive examination of the composition and structure of the LPS of $N$. perflava, $N$. sicca and N. catarrhalis (Adams, 1971; Adams et al., 1968; Adams, Tornabene \& Yaguchi, 1969) revealed marked differences among the LPS of the Neisseriaceae. Studies of LPS from different strains of $N$. gonorrhoeae (Stead et al., 1975) showed that all had the same sugar and fatty acid composition. There was no significant difference between the LPS of virulent gonococci or between penicillin-sensitive and penicillin-resistant strains. Since very few studies (Frasch \& Gotschlich, 1974) have been reported on N. meningitidis group B, the aim of this investigation was to determine some of the chemical properties of this LPS. 


\section{METHODS}

Bacteria. The strain used was N. meningitidis group B, obtained from Dr Malcolm S. Artenstein, Walter Reed Army Institute of Research Collection, Washington, D.C., U.S.A.

Cultivation and harvesting. The culture was grown on five Mueller-Hinton agar plates (Mueller \& Hinton, 1941) at $37^{\circ} \mathrm{C}$ in a candle jar. After $16 \mathrm{~h}$ the bacteria were resuspended and used to inoculate 1 litre of medium (Berman et al., 1970) in a 21 Erlenmeyer flask which was incubated at $37^{\circ} \mathrm{C}$ on a New Brunswick rotary shaker operating at $200 \mathrm{rev}$. $\mathrm{min}^{-1}$. After $5 \mathrm{~h}$ the absorbance $\left(A_{680}\right)$ reached 1.0 and the culture was inoculated into a 141 fermenter (New Brunswick, model MA 114) containing 91 of medium; the growth conditions were $37^{\circ} \mathrm{C}, 300 \mathrm{rev} . \mathrm{min}^{-1}$ and 21 air flow $\min ^{-1}$. After the absorbance reached 1.0 , the culture was transferred to a 2501 fermenter (New Brunswick, model FM 250) containing 1901 of medium; the growth conditions in this fermenter were $37^{\circ} \mathrm{C}, 200 \mathrm{rev} . \mathrm{min}^{-1}$ and 401 air flow $\mathrm{min}^{-1}$. The absorbance, read every $2 \mathrm{~h}$, reached a maximum of 1.8 after $10 \mathrm{~h}$ incubation; the culture was then cooled to $20^{\circ} \mathrm{C}$ and harvested into thimerosal (ethyl mercurithiosalicylic acid sodium salt, Fisher Scientific Co., Fairlawn, New Jersey, U.S.A.) at a concentration of $1 \mathrm{~g}$ per 51 culture fluid. The bacteria were collected in a Sharples centrifuge operating at $28000 \mathrm{rev} . \mathrm{min}^{-1}$.

Extraction and purification of LPS. The procedure for the extraction of LPS was that of Frasch \& Gotschlich (1974). Organisms (about $60 \mathrm{~g}$ wet wt) were suspended in a mixture of $600 \mathrm{ml}$ distilled water and $600 \mathrm{ml}$ $88 \%$ liquid phenol, and extracted at $70{ }^{\circ} \mathrm{C}$ for $20 \mathrm{~min}$ using a Sorvall Omnimixer. The homogenate was cooled in ice, centrifuged at $2000 \mathrm{~g}$ for $20 \mathrm{~min}$ and the aqueous phase was removed taking care not to include the interphase material. The crude LPS was precipitated from the aqueous phase with acetone at $-20^{\circ} \mathrm{C}$ ( 2 vol.) in the presence of sodium acetate $(20 \mathrm{mg}$ per $600 \mathrm{ml})$. The precipitate was collected by centrifugation ( $2000 \mathrm{~g}$ for $20 \mathrm{~min}$ ), washed several times with cold acetone, redissolved in distilled water, dialysed for $24 \mathrm{~h}$ at $4{ }^{\circ} \mathrm{C}$ with two to three changes of distilled water and lyophilized. The lyophilized LPS was suspended in distilled water $(80 \mathrm{ml})$ and centrifuged in the Beckman L2-75B ultracentrifuge at $80000 \mathrm{~g}$ for $1 \mathrm{~h}$; the absorbance of the supernatant was read at $260 \mathrm{~nm}$ and $280 \mathrm{~nm}$ to determine contamination with nucleic acid and protein. This procedure was repeated several times until the supernatant gave a negligible absorbance reading at $260 \mathrm{~nm}$ and $280 \mathrm{~nm}$. The final glassy pellet was resuspended in distilled water and lyophilized.

Hydrolysis and fractionation of LPS. To cleave LPS into lipid A and polysaccharide, samples $\left(5 \mathrm{mg} \mathrm{ml}^{-1}\right)$ were hydrolysed with $1 \%(\mathrm{w} / \mathrm{v})$ acetic acid at $100^{\circ} \mathrm{C}$ for 1 to $1.5 \mathrm{~h}$ until the precipitation of lipid A was complete (Wilkinson, Galbraith \& Lightfoot, 1973). The water-insoluble lipid A was removed from the hydrolysate by centrifugation at $2000 \mathrm{~g}$. The pellet was washed several times with water to remove contaminating polysaccharide and finally resuspended in water and lyophilized. The washings were pooled and combined with the water-soluble material (containing degraded or cleaved polysaccharide) and the solution was lyophilized.

High-voltage paper electrophoresis of LPS. LPS was hydrolysed with $0.25 \mathrm{M}-\mathrm{H}_{2} \mathrm{SO}_{4}$ for $24 \mathrm{~h}$ at $100{ }^{\circ} \mathrm{C}$ under $\mathrm{N}_{2}$. After hydrolysis, sulphate ions were precipitated by adding saturated $\mathrm{Ba}(\mathrm{OH})_{2}$ until the $\mathrm{pH}$ of the solution reached 5 to $5 \cdot 5$. The insoluble barium sulphate was removed by filtration and the filtrate was evaporated to dryness. Samples of this hydrolysate, together with appropriate standards, were subjected to electrophoresis for $3 \mathrm{~h}$ at $3000 \mathrm{~V}(120 \mathrm{~mA})$ on Whatman no. 1 paper $(18 \times 42 \mathrm{in})$ using pyridine/acetic acid/water (1:10:189, by vol.) $\mathrm{pH} 3.7$ as the solvent. Neutral sugars were detected by alkaline silver nitrate (Trevelyan, Procter \& Harrison, 1950), hexosamines by ninhydrin (Consden \& Gordon, 1948), and phosphates by the method of Hanes \& Isherwood (1949).

Thin-layer chromatography. Acid-hydrolysed samples of the cleaved polysaccharide $\left(1 \mathrm{M}-\mathrm{HCl}\right.$ at $100^{\circ} \mathrm{C}$ for $30 \mathrm{~min}$ ) were chromatographed on plates of silica gel GF (Analtech) in methanol/pyridine/10 $\mathrm{M}-\mathrm{HCl} /$ water (32:4:1:7, by vol.) (Wilkinson \& Galbraith, 1975). Standards of 2,6-diaminopimelic acid and ethanolamine were run with the samples. Acid ninhydrin (Consden \& Gordon, 1948) was used to detect 2,6-diaminopimelic acid and ethanolamine. In addition, ethanolamine was detected by spraying the plates with a $20 \%$ solution of fluorescamine in acetone and visualizing with ultraviolet light (Udenfriend et al., 1972).

Quantitative analysis. For amino acid analysis, the LPS preparation was hydrolysed in constant-boiling $6 \mathrm{M}-\mathrm{HCl}$ at $110{ }^{\circ} \mathrm{C}$ for $24 \mathrm{~h}$ under $\mathrm{N}_{2}$. After removal of $\mathrm{HCl}$ in vacuo, the amino acids were analysed on a Perkin Elmer KLA-5 amino acid analyser using ligand exchange chromatography. Protein was determined by the method of Lowry et al. (1951). For neutral sugar analysis, LPS was hydrolysed with $0 \cdot 25 \mathrm{M}-\mathrm{H}_{2} \mathrm{SO}_{4}$ for $24 \mathrm{~h}$ at $100{ }^{\circ} \mathrm{C}$ under $\mathrm{N}_{2}$, and then sulphate ions were removed as described for the acid hydrolysate used for high-voltage paper electrophoresis. Neutral sugars were identified and quantified by gas-liquid chromatography (g.l.c.) of their alditol acetate derivatives (Kim et al., 1967) on a Perkin-Elmer 900 gas chromatograph. Total carbohydrates were determined by the phenol-sulphuric acid method (Dubois et al., 1956). Hexosamines were determined by the method of Gatt \& Bermann (1966) and identified by g.l.c. of their alditol acetate derivatives using polyamide as the stationary phase (Neidermeier \& Tomana, 1974). Heptose and 2-keto-3-deoxyoctonic acid (KDO) were determined by the method of Osborn (1963). In addition, heptose 
Table 1. Chemical composition (as \% dry wt) of phenol/water-extracted lipopolysaccharide of $N$. meningitidis group $B$

\begin{tabular}{|c|c|c|c|}
\hline & Total LPS & Polysaccharide & Lipid A \\
\hline Lipid A & $35 \cdot 0$ & - & \\
\hline Fatty acid & $26 \cdot 6$ & - & $64 \cdot 7$ \\
\hline Phosphorus $\left(\mathrm{PO}_{4}{ }^{3-}\right)$ & $3.7(11 \cdot 1) \ddagger$ & $4 \cdot 0(12 \cdot 1) \ddagger$ & $3.9(9.3) \ddagger$ \\
\hline Protein & 1.0 & - & - \\
\hline Carbohydrate* & $15 \cdot 4$ & $21 \cdot 4$ & - \\
\hline Carbohydrate $\uparrow$ & $20 \cdot 8$ & $27 \cdot 0$ & - \\
\hline Galactose & $10 \cdot 8$ & $14 \cdot 0$ & - \\
\hline Glucose & $10 \cdot 0$ & $13 \cdot 0$ & - \\
\hline Glucosamine & $16 \cdot 5$ & $9 \cdot 7$ & $14 \cdot 6$ \\
\hline KDO & 3.0 & $6 \cdot 1$ & - \\
\hline
\end{tabular}

Table 2. Fatty acid composition of lipid $A$ and LPS and their corresponding molar ratios

\begin{tabular}{|c|c|c|c|c|c|c|}
\hline \multirow[b]{2}{*}{ Fatty acid* } & \multicolumn{2}{|c|}{ Percentage of total lipid } & \multicolumn{2}{|c|}{ Molar ratio } & \multicolumn{2}{|c|}{ Percentage of dry weigh } \\
\hline & Lipid A & LPS & Lipid A & LPS & Lipid A & LPS \\
\hline $\begin{array}{l}12: 0 \\
14: 0\end{array}$ & $\begin{array}{l}22 \cdot 6 \\
13 \cdot 7\end{array}$ & $\begin{array}{l}23.2 \\
11.6\end{array}$ & $\begin{array}{l}1.9 \\
1.0\end{array}$ & $\begin{array}{l}2 \cdot 3 \\
1 \cdot 0\end{array}$ & $\begin{array}{r}14 \cdot 6 \\
8 \cdot 8\end{array}$ & $\begin{array}{l}6 \cdot 1 \\
3 \cdot 1\end{array}$ \\
\hline $\mathrm{OH}-14: 0$ & $21 \cdot 0$ & $21 \cdot 0$ & $1 \cdot 6$ & 1.9 & $13 \cdot 6$ & $5 \cdot 5$ \\
\hline $15: 0$ & 1.5 & tr & - & - & $\operatorname{tr}$ & tr \\
\hline $16: 0$ & $9 \cdot 7$ & $7 \cdot 3$ & 0.6 & 0.6 & $6 \cdot 3$ & 1.7 \\
\hline $16: 1$ & 8.9 & 10.6 & 0.6 & 0.8 & $5 \cdot 7$ & $2 \cdot 8$ \\
\hline $18: 0$ & $\operatorname{tr}$ & $\operatorname{tr}$ & - & - & $\operatorname{tr}$ & $\operatorname{tr}$ \\
\hline $18: 1$ & $21 \cdot 8$ & $23 \cdot 2$ & $1 \cdot 3$ & $1 \cdot 6$ & $14 \cdot 1$ & $6 \cdot 1$ \\
\hline
\end{tabular}

tr, Trace $(=<1 \%) ;-$, not detected.

* The first number indicates the carbon chain length; the second number is the number of double bonds.

was determined by the g.l.c. of its alditol acetate derivative (Holme et al., 1968), phosphorus by the method of Chen, Toribara \& Warner (1956) and sialic acid by the method of Warren (1959). The total fatty acid content of LPS was determined using the titrimetric procedure of Lauwerys (1969). Individual fatty acids were identified by g.l.c. of their methyl ester derivatives using a $183 \times 0.2 \mathrm{~cm}$ glass column containing $20 \%$ DEGS, at column, manifold, and injector temperatures of 170,230 and $200^{\circ} \mathrm{C}$, respectively; helium was the carrier gas (Schlenk \& Gellerman, 1960).

Assay for endotoxin activity. LPS was tested for endotoxin activity by the limulus-lysate assay (Yin $e t$ al., 1972). Tubes were incubated at $37^{\circ} \mathrm{C}$ for $30 \mathrm{~min}$.

\section{RESULTS}

The yield of LPS was $0.22 \%(w / w)$ of the wet organisms or cell paste. The LPS preparation gave firm gelation in the limulus-lysate assay similar in degree to that given by the standard E. coli LPS at $5 \mathrm{ng} \mathrm{ml}^{-1}$ (Mallinckrodt, St Louis, U.S.A.) which was used as a positive control.

\section{Analysis of lipopolysaccharide}

The LPS preparation contained negligible amounts of nucleic acid as shown by the amount of ribose present $(0.05 \%, \mathrm{w} / \mathrm{w})$ and the very low absorbance at $260 \mathrm{~nm}$. The protein content of the LPS was $1.0 \%(\mathrm{w} / \mathrm{w})$ and on acid hydrolysis revealed a trace amount of alanine. Electrophoresis of acid-hydrolysed LPS revealed the presence of neutral sugars, glucosamine and a phosphate-containing compound. The neutral sugars were subsequently identified by g.l.c. as glucose and galactose. Thin-layer chromatography of the polysaccharide fraction 
revealed trace amounts of 2,6-diaminopimelic acid indicating a slight degree of contamination with peptidoglycan. However, ethanolamine was not detected. The chemical analysis of the LPS is given in Table 1. Heptose was not detected either by g.l.c. or by the cysteine$\mathrm{H}_{2} \mathrm{SO}_{4}$ reagent. G.l.c. revealed a trace amount of methyl pentose. Neutral sugars, identified as their alditol acetate derivatives, were present in a molar ratio of galactose to glucose of $1: 1$. Sialic acid was not detected.

\section{Lipid $A$ and partly degraded polysaccharide}

Mild acid hydrolysis of LPS with $1 \%$ acetic acid at $100{ }^{\circ} \mathrm{C}$ cleaved lipid A from the polysaccharide moiety. The lipid A released was approximately $35 \%$ of the total LPS based on the weight of the insoluble white precipitate obtained. The fatty acid compositions of lipid A and whole LPS were identical (Table 2) whereas the soluble cleaved polysaccharide was lipid-free. Polysaccharide recovered from the acid hydrolysate comprised $62.5 \%$ of the LPS (based on the weight of freeze-dried material) and had glucosamine and phosphorus contents of $9.7 \%$ and $4.0 \%$ respectively (Table 1 ). Fatty acids liberated from lipid A by alkaline hydrolysis $\left(4 \mathrm{M}-\mathrm{NaOH}\right.$ for $4 \mathrm{~h}$ at $\left.100^{\circ} \mathrm{C}\right)$ were analysed and identified as their methyl ester derivatives by g.l.c. The major fatty acids present were $\beta$-hydroxymyristic acid, lauric acid, oleic acid and myristic acid. Palmitic acid and palmitoleic acid were present in smaller amounts (Table 2).

\section{DISCUSSION}

The LPS isolated from $N$. meningitidis group B contained glucose, galactose, glucosamine, KDO, lipid A and phosphorus. The fatty acid composition showed a high proportion of fatty acids with even numbers of carbon atoms, as is in other Gram-negative bacteria. One of the major fatty acids present, second only in amount to $\beta$-hydroxymyristic and lauric acids, was oleic acid, $\mathrm{C}_{18: 1}$. This, and $\beta$-hydroxymyristic and lauric acids, seem to be fatty acid components common to all Neisseriaceae (Yamakawa \& Ueta, 1964).

The presence of galactose in the isolated LPS distinguishes it from the LPS of both $N$. perflava (Adams et al., 1968) and $N$. sicca (Adams, 1971) which lack this sugar. Galactose is, however, a component of LPS of other Neisseria species such as $N$. catarrhalis (Adams et al., 1969), N. meningitidis group C (Mergenhagen et al., 1963) and $N$. gonorrhoeae (Stead et al., 1975). Sialic acid was not present in the isolated LPS, in contrast to the LPS of $N$. meningitidis group $\mathrm{C}$, although both group B and $\mathrm{C}$ have sialic acid as the major constituent of their capsular polysaccharide. Sialic acid was present in the crude LPS but was removed by ultracentrifugation. Another feature of this LPS was the absence of heptose and in this respect it resembles the LPS of $N$. sicca (Adams, 1971) and N. catarrhalis (Adams et al., 1969).

Examination of the LPS of $N$. meningitidis group B has shown that its composition is markedly different from that of $N$. meningitidis group C, and is also different from the LPS of $N$. perflava, $N$. sicca, $N$. gonorrhoede and $N$. catarrhalis. Thus no common pattern exists among the LPS of Neisseriaceae.

We are sincerely grateful to Dr Arpi Hagopian for discussion.

\section{REFERENCES}

AdAms, G. A. (1971). Structural investigations on a cell-wall lipopolysaccharide from Neisseria sicca. Canadian Journal of Biochemistry 49, 243250.

Adams, G. A., Kates, M., Shaw, D. H. \& Yaguchi, M. (1968). Studies on the chemical constitution of cell-wall lipopolysaccharide from Neisseria perflava. Canadian Journal of Biochemistry 46, 11751184.
Adams, G. A., Tornabene, T. G. \& Yaguchi, M. (1969). Cell-wall lipopolysaccharide from Neisseria catarrhalis. Canadian Journal of Microbiology 15, 365-374.

Berman, S., Altieri, P. L., Groffinger, A. \& Lowenthal, J. P. (1970). Pilot-scale production of group A and group C meningococcal polysaccharide immunogens. Infection and Immunity 2 , 640-643. 
Borvin, A. \& Mesrobeanu, L. (1933). Chemical composition of bacteria. 'Acid soluble' nitrogen and phosphorus compounds. Comptes rendus des séances de la Société de biologie et des ses filiales 112, 76-79.

BooR, A. K. \& Mrller, P. (1944). A carbohydratelipid fraction of gonococcus and meningococcus. Journal of Infectious Diseases 75, 47-57.

BuRRows, W. (1951). Endotoxins. Annual Review of Microbiology 5, 181-196.

Chen, P. S., JR, Toribara, T. Y. \& Warner, H. (1956). Microdetermination of phosphorus. Analytical Chemistry 28, 1756-1758.

Consden, R. \& Gordon, A. H. (1948). Effect of salt on partition chromatograms. Nature, London 162, 180-181.

Dubois, M., Gilles, K. A., Hamilton, J. K., Rebers, P. A. \& SMith, F. (1956). Colorimetric method for determination of sugars and related substances. Analytical Chemistry 28, 350-356.

Frasch, C. E. \& Gotschlich, E. C. (1974). An outer membrane protein of Neisseria meningitidis group B responsible for serotype specificity. Journal of Experimental Medicine 140, 87-104.

GatT, R. \& BermanN, E. R. (1966). A rapid procedure for the estimation of amino sugars on a micro scale. Analytical Biochemistry 15, 167-171.

HANes, C. S. \& IsHerwood, F. A. (1949). Separation of the phosphoric esters on the filter paper chromatogram. Nature, London 164, 1107-1112.

Holme, T., Lindberg, A. A., GaregG, P. J. \& ONN, T. (1968). Chemical composition of cell-wall polysaccharide of rough mutants of Salmonella typhimurium. Journal of General Microbiology 52, 45-54.

KIM, J. H., Shome, B., Liao, T. S. \& Pierce, J. G. (1967). Analysis of neutral sugars by gas-liquid chromatography of alditol acetates: application of thyrotropic hormone and other glycoproteins. Analytical Biochemistry 20, 258-274.

KUN, E. (1947). Effect of meningococcal endotoxins on histamine content of blood and tissue from rabbits. Proceedings of the Society for Experimental Biology and Medicine 66, 197-201.

KuN, E. \& ABOoD, L. G. (1949). Mechanism of inhibition of glycogen synthesis by endotoxins of Salmonella aertrycke and type I meningococcus. Proceedings of the Society for Experimental Biology and Medicine 71, 362-364.

LAUWERYS, R. R. (1969). Colorimetric determination of free fatty acids. Analytical Biochemistry 32, 331-333.

Lowry, O. H., Rosebrough, N. J., Farr, A. L. \& RANDALL, R. J. (1951). Protein measurement with the Folin phenol reagent. Journal of Biological Chemistry 193, 265-275.

Mergenhagen, S. E., Martin, G. R. \& SchiffMANN, E. (1963). Studies on an endotoxin of a group C Neisseria meningitidis. Journal of Immuno$\log y$ 90, 312-317.
MuelleR, J. H. \& HiNTON, J. (1941). A proteinfree medium for primary isolation of gonococcus and meningococcus. Proceedings of the Society for Experimental Biology and Medicine 48, 330-333.

NEIDERMEIER, W. \& TOMANA, M. (1974). Gas chromatographic analysis of hexosamines in glycoproteins. Analytical Biochemistry 57, 363368.

OsBorn, M. J. (1963). Studies on the gram-negative cell-wall. I. Evidence for the role of 2-keto-3deoxyoctonate in the lipopolysaccharide of Salmonella typhimurium. Proceedings of the National Academy of Sciences of the United States of America 50, 499-506.

Scherp, H. W. (1955). Neisseria and Neisserial infections. Annual Review of Microbiology 9, 319-334.

Schlenk, H. \& Gellerman, J. L. (1960). Esterification of fatty acids with diazomethane on a small scale. Analytical Chemistry 32, 1412-1414.

Stead, A., MaIn, J. S., Ward, M. E. \& WatT, P. J. (1975). Studies on lipolysaccharides isolated from strains of Neisseria gonorrhoeae. Journal of General Microbiology 88, 123-131.

THomas, L. (1954). The physiological disturbances produced by endotoxins. Annual Review of Physiology 16, 467-490.

Trevelyan, W. E., Procter, D. P. \& Harrison, J. S. (1950). Detection of sugars on paper chromatograms. Nature, London 166, 444-445.

Udenfriend, S., Stern, S., Bohlen, P., Dairman, W., LeImgruber, W. \& Weigele, M. (1972). Applications of fluorescamine. A new reagent for the assay of amino acids, peptides, proteins and other primary amines in the picomole range. Science 178, 871-872.

WARREN, L. (1959). The thiobarbituric acid assay of sialic acids. Journal of Biological Chemistry 234, 1971-1975.

Wilkinson, S. G. \& Galbraith, L. (1975). Studies of lipopolysaccharides from Pseudomonas aeruginosa. European Journal of Biochemistry 52, 331343.

Wilkinson, S. G., Galbraith, L. \& Lightfoot, G. (1973). Cell walls, lipids and lipopolysaccharides of Pseudomonas species. European Journal of Biochemistry 33, 158-174.

YAMAKAWA, T. \& UeTA, N. (1964). Gas chromatographic studies of microbial components. I. Carbohydrate and fatty acid constitution of Neisseria. Japanese Journal of Experimental Medicine 34, 361-374.

Yin, E. T., Galanos, C., Kinsky, S., Bradshaw, R., Wessler, S. \& LüderITZ, O. (1972). Picogram sensitivity assay for endotoxin: Gelation of Limulus polyphemus blood cell lysate induced by purified lipopolysaccharides and lipid A from gram-negative bacteria. Biochimica et biophysica acta 261, 284-289. 